\title{
Cardiovascular outcomes in the first trial of antihypertensive therapy guided by self-measured home blood pressure
}

\author{
Kei Asayama ${ }^{1,2}$, Takayoshi Ohkubo ${ }^{2,3}$, Hirohito Metoki ${ }^{4}$, Taku Obara ${ }^{4}$, Ryusuke Inoue ${ }^{5}$, Masahiro Kikuya ${ }^{2}$, \\ Lutgarde Thijs ${ }^{1}$, Jan A Staessen ${ }^{1,6}$ and Yutaka Imai ${ }^{2}$, on behalf of Hypertension Objective Treatment Based \\ on Measurement by Electrical Devices of Blood Pressure (HOMED-BP) investigators
}

Hypertension guidelines recommend blood pressure self-measurement at home (HBP), but no previous trial has assessed cardiovascular outcomes in hypertensive patients treated according to HBP. The multicenter Hypertension Objective Treatment Based on Measurement by Electrical Devices of Blood Pressure (HOMED-BP; 2001-2010) trial involved 3518 patients (50\% women; mean age 59.6 years) with an untreated systolic/diastolic HBP of $135-179 / 85-119 \mathrm{~mm} \mathrm{Hg}$. In a $2 \times 3$ design, patients were randomized to usual control (125-134/80-84 mm Hg (UC)) vs. tight control $(<125 /<80 \mathrm{~mm} \mathrm{Hg}$ (TC)) of HBP and to initiation of drug treatment with angiotensin converting enzyme inhibitors, angiotensin receptor blockers or calcium channel blockers. During follow-up, a computer algorithm automatically generated treatment recommendations based on HBP. At the last follow-up (median 5.3 years), TC patients used more antihypertensive drugs than UC patients (1.82 vs. 1.74 defined daily doses, $P=0.045)$ and had a greater HBP reduction $(21.3 / 13.1 \mathrm{~mm} \mathrm{Hg} v$ s. $22.7 / 13.9 \mathrm{~mm} \mathrm{Hg}, P=0.018 / 0.020)$, but they less frequently achieved the lower HBP targets $(37.4$ vs. $63.5 \%, P<0.0001)$. The primary end point, cardiovascular death plus stroke and myocardial infarction, occurred in 25 UC and 26 TC patients (hazard ratio, 1.02; 95\% confidence interval, 0.59-1.77; $P=0.94)$. Rates were similar $(P \geqslant 0.13)$ in the three drug groups. In all patients combined, the risk of the primary end point independently increased by $41 \%(6-89 \% ; P=0.019)$ and $47 \%(15-87 \% ; P=0.0020)$ for a 1 -s.d. increase in baseline $(12.5 \mathrm{~mm} \mathrm{Hg})$ and follow-up $(13.2 \mathrm{~mm} \mathrm{Hg})$ systolic HBP. The 5 -year risk was minimal $(\leqslant 1 \%)$ if on-treatment systolic HBP was $131.6 \mathrm{~mm} \mathrm{Hg}$ or less. HOMED-BP proved the feasibility of adjusting antihypertensive drug treatment based on HBP and suggests that a systolic HBP level of $130 \mathrm{~mm} \mathrm{Hg}$ should be an achievable and safe target.

Hypertension Research (2012) 35, 1102-1110; doi:10.1038/hr.2012.125; published online 16 August 2012

Keywords: antihypertensive drug treatment; blood pressure control; home blood pressure; randomized clinical trial

\section{INTRODUCTION}

According to expert committees, self-measurement of blood pressure at home (HBP) is the state-of-the-art in the diagnosis and management of hypertension. ${ }^{1-3}$ As exemplified by the Ohasama and Finn-Home studies, ${ }^{4,5}$ blood pressure self-monitoring offers several of the well-recognized advantages of the more complex approach of ambulatory monitoring. The greater number of readings and the absence of the white-coat effect contribute to higher diagnostic accuracy, compared with conventional sphygmomanometry. ${ }^{3}$ If automated devices are used, then self-recorded blood pressure values are free of observer bias. ${ }^{4}$ Moreover, self-measurement of blood pressure increases adherence to antihypertensive treatment and allows reducing the number of clinic visits required for the diagnosis and treatment of hypertension. ${ }^{6,7}$

The THOP (Treatment of Hypertension Based on Home or Office Blood Pressure) ${ }^{8}$ and the HOMERUS (Home Versus Office Measurement - Reduction of Unnecessary Treatment $)^{9}$ trials demonstrated that adjustment of antihypertensive treatment based on HBP led to less intensive drug treatment with no differences in general well-being or target organ damage. However, no previous trial has assessed the long-term cardiovascular outcomes of antihypertensive therapy guided by self-measured HBP. The Hypertension Objective Treatment Based on Measurement by Electrical Devices of Blood Pressure (HOMED-BP $)^{10}$ explored to what extent long-term

${ }^{1}$ Department of Cardiovascular Diseases, Division of Hypertension and Cardiovascular Rehabilitation, Studies Coordinating Centre, University of Leuven, Leuven, Belgium; ${ }^{2}$ Department of Planning for Drug Development and Clinical Evaluation, Tohoku University Graduate School of Pharmaceutical Sciences, Sendai, Japan; ${ }^{3}$ Department of Health Science, Shiga University of Medical Science, Otsu, Japan; ${ }^{4}$ Department of Development and Environmental Medicine, Tohoku University Graduate School of Medicine, Sendai, Japan; ${ }^{5}$ Department of Medical Informatics, Tohoku University Graduate School of Medicine, Sendai, Japan and ${ }^{6}$ Department of Epidemiology, Maastricht University, Maastricht, The Netherlands

Correspondence: Dr Y Imai, Department of Planning for Drug Development and Clinical Evaluation, Tohoku University Graduate School of Pharmaceutical Sciences, 2-1 Seiryo-cho, Aoba-ku, Sendai 980-8575, Japan.

E-mail: rinsyo@mail.pharm.tohoku.ac.jp

Received 16 May 2012; revised 27 June 2012; accepted 28 June 2012; published online 16 August 2012 
antihypertensive treatment guided by self-measured HBP impacted on cardiovascular outcomes in patients randomized to usual $v s$. tight control (UC vs. TC) and to initiation of treatment with different classes of antihypertensive drugs.

\section{METHODS}

\section{Study design}

The HOMED-BP protocol $^{10}$ complies with the Helsinki declaration for investigation of human subjects ${ }^{11}$ and was approved by the Ethics Committees of the Tohoku University Graduate School of Medicine. HOMED-BP is registered with the UMIN Clinical Trial Registry, number C000000137 (http://www.umin.ac.jp/ctr).

HOMED-BP is a clinical trial with PROBE (prospective randomized openblinded end point evaluation $)^{12}$ design. Patients with mild-to-moderate hypertension with a minimum age of 40 years were recruited from 457 general practices throughout Japan. Treatment naïve patients as well as previously treated patients, whose antihypertensive drug treatment could be discontinued for at least 2 weeks, qualified for enrollment. Off treatment, they had to maintain a self-measured HBP of $135-179 \mathrm{~mm} \mathrm{Hg}$ systolic or 85-119 mm Hg diastolic. Patients meeting the systolic criteria for the HBP did not qualify if the diastolic was $<65 \mathrm{~mm} \mathrm{Hg}$, while those meeting the diastolic range were excluded if systolic blood pressure was $<110 \mathrm{~mm} \mathrm{Hg}$. The clinic blood pressure off treatment had to be lower than $220 \mathrm{~mm} \mathrm{Hg}$ systolic and $125 \mathrm{~mm} \mathrm{Hg}$ diastolic. Eligible patients should have no contra-indication for treatment with angiotensin converting enzyme inhibitors (ACEIs), angiotensin receptor blockers (ARBs), calcium channel blockers (CCBs), $\beta$-blockers, $\alpha$-blockers or diuretics. The presence of risk factors other than hypertension or a previous history of cardiovascular disease did not lead to exclusion.

Randomization was based on a computerized random number function with a minimization algorithm running on a central server at Tohoku University, considering sex, age, and the systolic and diastolic levels of the HBP. In a $2 \times 3$ design, eligible patients were randomized to UC vs. TC of self-measured HBP and to initiation of antihypertensive drug treatment with ACEIs, ARBs or CCBs. UC was an HBP ranging from 125 to $134 \mathrm{~mm} \mathrm{Hg}$ systolic and from 80 to $84 \mathrm{~mm} \mathrm{Hg}$ diastolic. TC was HBP values $<125 \mathrm{~mm} \mathrm{Hg}$ systolic and $<80 \mathrm{~mm} \mathrm{Hg}$ diastolic. After randomization, the clinical investigators followed the study participants at intervals of $\sim 2-4$ weeks in general practice and 4-8 weeks at hospital outpatient clinics.

\section{Measurement and adjustment of antihypertensive treatment after randomization}

At each visit, after the patients had rested in the sitting position for $2 \mathrm{~min}$, practitioners obtained two consecutive measurements of blood pressure and heart rate using the validated ${ }^{13}$ oscillometric OMRON HEM-907IT device (Omron Healthcare, Kyoto, Japan). The clinic blood pressure was the average of these two readings. Patients received spoken and written instructions on blood pressure self-measurement and the utilization of the validated ${ }^{14}$ oscillometric OMRON HEM-747IC-N monitors (Omron Healthcare). They were asked to measure blood pressure and heart rate after $2 \mathrm{~min}$ rest in the sitting position every morning during the whole study. They had to obtain these measurements within $1 \mathrm{~h}$ of awakening, before breakfast and before taking antihypertensive medication. The OMRON HEM-747IC-N stores up to 350 readings in its memory.

At each visit, the HBP values stored in memory were uploaded via a local computer to the server at Tohoku University. The HBP used for determining eligibility and treatment adjustments at each visit was the average of the morning readings available over 5 days immediately preceding the visit. These values were automatically calculated by the server and immediately displayed on the screen of the local computer in the practices along with an advice for treatment adjustment based on a computerized algorithm running on the central server. The algorithm followed the 1997 recommendations of the Joint National Committee ${ }^{15}$ and the 1999 guidelines of the World Health Organization and the International Society of Hypertension ${ }^{16}$ and consisted of five steps. First, the doctors started the first-line drug to which the patients had been randomized (ACEI, ARB or CCB) at a lower dose, which was increased in the second and third steps. The third step also included association of a diuretic. The fourth step involved the association of a $\alpha$ - or $\beta$-blocker and the fifth step the addition of any antihypertensive agent. When the HBP was $<110 \mathrm{~mm} \mathrm{Hg}$ systolic or $65 \mathrm{~mm} \mathrm{Hg}$ diastolic, treatment was tailored down to avoid orthostatic hypotension.

\section{Definitions}

We coded end points according to the tenth revision of the International Classification of Diseases (ICD-10). As in several other trials, ${ }^{17}$ the primary end point of HOMED-BP was a composite of cardiovascular death (ICD-10 codes I00-I99), non-fatal myocardial infarction (I21) and non-fatal stroke (I60, I61 and I63). Fatal and non-fatal stroke did not include transient ischemic attacks. Ischemic heart disease encompassed death from angina pectoris (I20), cardiac arrest (I46) and nonfatal myocardial infarction (I21). A broader composite cardiovascular end point included the events of the primary end point plus transient ischemic attack (G45), angina pectoris (I20), coronary atherosclerosis (I70) and fatal and non-fatal heart failure (I50). The end point committee, which was unaware of the patients' randomization, adjudicated all events.

Electrocardiographic left ventricular hypertrophy was as a Sokolow-Lyon index larger than $35 \mathrm{~mm}(3.5 \mathrm{mV})^{18}$ or a Cornell voltage $\times$ QRS duration index larger than $2440 \mathrm{~mm} \times \mathrm{ms}^{19}{ }^{19}$ Diabetes mellitus was a fasting plasma glucose of $7.0 \mathrm{mmoll}^{-1}\left(126 \mathrm{mg} \mathrm{dl}^{-1}\right)$ or more, an $\mathrm{HbA}_{1 \mathrm{c}}$ of $6.5 \%$ or more, ${ }^{20}$ or treatment with oral antidiabetic drugs or insulin. Hypercholesterolemia was a total cholesterol of $5.69 \mathrm{mmoll}^{-1}\left(220 \mathrm{mg} \mathrm{dl}^{-1}\right)$ or more, a documented history of hypercholesterolemia, or taking lipid-lowering drug treatment. We used the defined daily dose (DDD; ${ }^{21}$ Supplementary Table S1), version 2011, to quantify the use of antihypertensive drugs in each participant at each visit.

\section{Sample size}

Our original sample-size calculations assumed a rate of the primary end point in the UC group of 13.0 events per 1000 patient-years, as observed in the treated participants enrolled in the Ohasama study, ${ }^{22}$ who had a self-measured HBP averaging from 125 to $134 \mathrm{~mm} \mathrm{Hg}$ systolic and from 80 to $84 \mathrm{~mm} \mathrm{Hg}$ diastolic. To detect a $20 \%$ difference in the incidence of the primary end point between usual and tight blood pressure control with 5\% significance and $90 \%$ power, 9000 patients had to be randomized and followed up for 7 years (63000 patient-years).

Screening of patients started in May 2001, and the first patient was randomized on 6 June 2001 (Supplementary Figure S1). However, on 16 March 2009, the Management Committee decided to stop the HOMED-BP trial, because the difference in the self-measured systolic pressure was smaller than projected and because the primary end point in the two treatment groups combined ran at only 2.96 events per 1000 patient-years. Therefore, the last patient was randomization on 7 October 2009, and the last terminating visit took place on 30 April 2010.

\section{Statistical analysis}

For database management and statistical analysis, we used SAS software, version 9.2 (SAS Institute, Cary, NC, USA). For comparison of means and proportions, we applied the $Z$-test for large samples and the $\chi^{2}$-statistic, respectively. We computed Pearson correlation coefficients between blood pressures levels measured at baseline and follow-up.

We analyzed the outcome results according to the intention-to-treat principle and considering only the first event of each outcome. We computed $95 \%$ confidence intervals (CIs) of rates using the normal approximation. ${ }^{23} \mathrm{We}$ compared the incidence of events between randomized groups by KaplanMeier survival function estimates and the log-rank test.

In an attempt to determine the optimal HBP to be achieved by treatment, we applied Cox regression pooling all participants in a cohort analysis. The ontreatment blood pressure was taken at the last available visit in patients without event or recorded 6 months before an event. This 6-month interval minimizes bias due to the fall or rise in the on-treatment blood pressure as a forerunner of an event. ${ }^{24}$ Missing values were imputed using a Markov singlechain Monte Carlo method. ${ }^{25}$ The imputation model included all co-variables entered in the Cox model. Sensitivity analyses were conducted to ascertain that imputations did not weaken or inflate the reported associations. To calculate 
the on-treatment HBP level that yielded a 5-year absolute risk of $1 \%$, we used a bootstrap procedure, as described elsewhere. ${ }^{26,27}$

\section{RESULTS}

\section{Baseline characteristics}

Of 5211 patients enrolled in the run-in period (Figure 1), 3518 $(67.5 \%)$ were randomized to either UC $(n=1759)$ or TC $(n=1759)$ of the HBP and to initiation of antihypertensive drug treatment with ACEIs $(n=1172)$, ARBs $(n=1175)$ or CCBs $(n=1171)$. Of 1693 non-randomized patients, $727(42.9 \%)$ had an HBP outside the eligibility range, $14(0.8 \%)$ had a clinic blood pressure exceeding the safety limits, 76 (4.5\%) withdrew consent, 69 (4.1\%) defected before randomization and $8(0.5 \%)$ had severe intercurrent disease during the run-in period. In 445 patients (26.3\%) doctors did not collect or transfer all required information, and 261 patients (15.4\%) were lost due to computer or network downtime.

At baseline, all randomized groups were similar for the distributions of sex, age, home and clinic blood pressures and heart rates, body mass index, serum cholesterol, plasma glucose, smoking and drinking habits, and previous cardiovascular complications (Table 1). Among 2792 patients with electrocardiograms at baseline, the prevalence of electrocardiographic left ventricular hypertrophy was similar in all groups $(9.5-10.3 \% ; P \geqslant 0.80)$.

\section{Tight $v s$. usual blood pressure control}

Patients were recruited over 8 years (Supplementary Figure S1) and the median follow-up was 5.31 years (interquartile range 3.08-6.91). The number of patient-years in the UC and TC groups amounted to 8567 and 8736

Treatments administered. At 6 months and at the last follow-up visit (Figure 2), the mean (s.d.) DDD of antihypertensive medications was slightly but significantly higher $(P=0.002$ and $P=0.045)$ in the TC than in UC group: 1.64 (0.92) vs. $1.54(0.91)$ and $1.82(1.19)$ vs. 1.74 (1.12), respectively. The rate at which the automatically generated treatment recommendations were implemented was significantly lower in the TC than in UC group, averaging 22.1 and $27.4 \%$ within the first 2 years of randomization $(P<0.0001)$, when most of the treatment adjustments took place.

Achieved blood pressure. At 6 months and at the last available visit, systolic/diastolic HBPs had fallen $(P<0.0001)$ by a mean (s.d.) of 16.8
(14.6)/9.2 (8.4) $\mathrm{mm} \mathrm{Hg}$ and $21.3(16.0) / 13.1(9.5) \mathrm{mm} \mathrm{Hg}$ in the UC group, and by $18.2(14.4) / 9.9(8.4) \mathrm{mm} \mathrm{Hg}$ and 22.7 (15.6)/13.9 (9.9) $\mathrm{mm} \mathrm{Hg}$ in the TC group (Figure 2). At 6 months and at the last available visit, systolic/diastolic clinic blood pressures had fallen by $20.1(19.6) / 11.7$ (12.2) $\mathrm{mm} \mathrm{Hg}$ and 23.8 (21.0)/15.2 (13.3) $\mathrm{mm} \mathrm{Hg}$ in the UC group, and by $21.8(19.8) / 12.3$ (12.2) $\mathrm{mm} \mathrm{Hg}$ and 24.9 (21.2)/ 16.0 (13.4) $\mathrm{mm} \mathrm{Hg}$ in the TC group. At the last available visit, in 3147 patients with a follow-up measurement of the HBP after randomization, the baseline-adjusted between-group differences (UC minus TC) averaged systolic 1.3 (15.8) $\mathrm{mm} \mathrm{Hg}(\mathrm{CI}, 0.2-2.4 \mathrm{~mm} \mathrm{Hg} ; P=0.018$; Figure 2) and diastolic 0.8 (9.7) $\mathrm{mm} \mathrm{Hg}$ (CI, $0.1-1.5 \mathrm{~mm} \mathrm{Hg}$; $P=0.020$ ). The corresponding differences in the clinic blood pressure in 3083 patients with such measurement after randomization were systolic 1.1 (21.1) $\mathrm{mm} \mathrm{Hg}(\mathrm{CI},-0.4$ to $2.6 \mathrm{~mm} \mathrm{Hg} ; P=0.14)$ and diastolic 0.7 (13.3) $\mathrm{mm} \mathrm{Hg}(\mathrm{CI},-0.2$ to $1.7 \mathrm{~mm} \mathrm{Hg} ; P=0.12)$.

Blood pressure control. The proportion of patients reaching the target levels of HBP at the end of follow-up was significantly (all $P<0.0001$ ) lower in the TC than in UC group: $42.6 v s .68 .3 \%$ for systolic pressure, 68.3 vs. $82.2 \%$ for diastolic pressure and 37.4 vs. $63.5 \%$ for both systolic and diastolic pressure.

Outcome. The primary outcome, a composite of cardiovascular death, non-fatal stroke and non-fatal myocardial infarction, occurred in 25 patients of the UC group and 26 randomized to TC of the HBP, resulting in cumulative rates of 2.93 and 3.00 end points per 1000 patient-years (Table 2; Figure 3). The percentage difference in the rate of the primary end point (TC minus UC) was $2 \%$ (CI, -42 to 74 ; $P=0.93$ ). There were no differences in the risk of the broader composite cardiovascular end point, stroke, ischemic heart disease and total mortality between patients randomized to usual or tight blood pressure control (Table 2). Among patients with ischemic heart disease, only 12 (7 and 5 in the UC and TC groups) experienced myocardial infarction. All-cause mortality included only eight cardiovascular deaths (five and three in the UC and TC groups). The number of patients withdrawn for severe side effects amounted to $3(0.17 \%)$ and $4(0.23 \%)$ in the UC and TC groups, respectively.

\section{Comparison of drug classes to initiate treatment}

The number of patient-years in patients randomized to ACEIs, ARBs and CCBs amounted to 5829, 5734 and 5741, respectively. The final on-treatment systolic/diastolic HBP was similar in the three groups

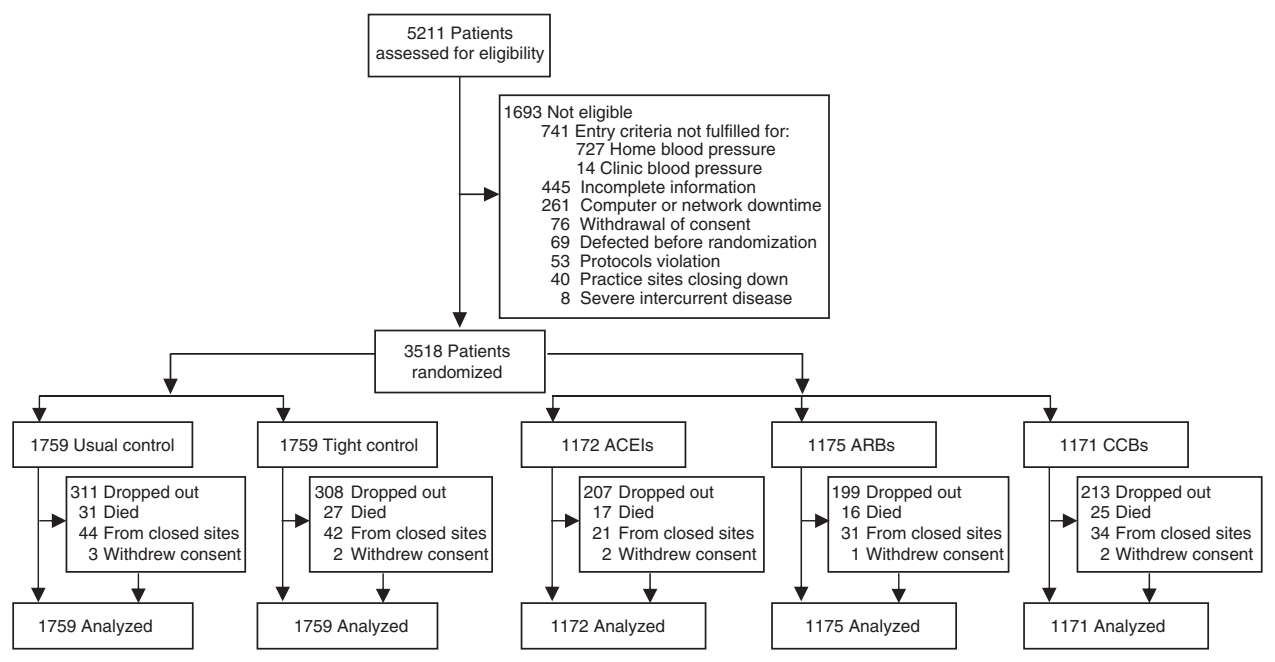

Figure 1 Trial profile. 
Table 1 Baseline characteristics of HOMED-BP participants

\begin{tabular}{|c|c|c|c|c|c|}
\hline Characteristic & Usual control & Tight control & ACEIS & $A R B s$ & CCBs \\
\hline Number & 1759 & 1759 & 1172 & 1175 & 1171 \\
\hline \multicolumn{6}{|l|}{ Mean characteristic (s.d.) } \\
\hline Age (years) & $59.6(9.9)$ & $59.6(10.2)$ & $59.8(10.0)$ & $59.5(10.1)$ & $59.5(10.1)$ \\
\hline Body mass index $\left(\mathrm{kg} \mathrm{m}^{-2}\right)$ & $24.4(3.5)$ & $24.4(3.4)$ & $24.5(3.6)$ & $24.5(3.4)$ & $24.2(3.3)$ \\
\hline \multicolumn{6}{|l|}{ Home measurements } \\
\hline Systolic pressure & $151.7(12.6)^{*}$ & $151.5(12.3)^{*}$ & $151.6(12.5)^{*}$ & $151.6(12.4)^{*}$ & $151.6(12.6)^{*}$ \\
\hline Diastolic pressure & 89.9 (10.3) & $90.0(9.8)$ & $89.8(10.0)$ & $89.8(10.1)$ & $90.1(9.9)$ \\
\hline Heart rate & $69.4(9.5)^{*}$ & $68.8(9.4)^{*}$ & $69.0(9.2)^{*}$ & $69.0(9.5)^{*}$ & $69.1(9.5)^{*}$ \\
\hline \multicolumn{6}{|l|}{ Clinic measurements } \\
\hline Systolic pressure & $154.1(17.5)$ & $154.3(17.5)$ & $153.9(17.5)$ & $153.9(17.1)$ & 154.8 (17.9) \\
\hline Diastolic pressure & $90.0(12.1)$ & $90.4(12.2)$ & $89.9(12.4)$ & $90.1(11.7)$ & $90.6(12.5)$ \\
\hline Heart rate & $74.9(11.8)$ & $75.0(12.0)$ & 75.3 (11.9) & $74.6(12.1)$ & $75.0(11.7)$ \\
\hline \multicolumn{6}{|l|}{ Biochemical measurements } \\
\hline Plasma glucose $\left(\mathrm{mmol}^{-1}\right)$ & $5.88(1.78)$ & $5.81(1.65)$ & $5.88(1.73)$ & $5.85(1.77)$ & $5.80(1.63)$ \\
\hline Serum total cholesterol $\left(\mathrm{mmol}^{-1}\right)$ & $5.46(0.93)$ & $5.45(0.90)$ & $5.44(0.88)$ & $5.50(0.95)$ & $5.42(0.92)$ \\
\hline \multicolumn{6}{|l|}{ Number with characteristic (\%) } \\
\hline Women & $883(50)$ & $880(50)$ & $589(50)$ & $588(50)$ & $586(50)$ \\
\hline Current smoking & $381(22)$ & $389(22)$ & $250(21)$ & $266(23)$ & $255(22)$ \\
\hline Past smoker & $293(17)$ & 305 (17) & $184(16)$ & $199(17)$ & $216(18)$ \\
\hline Current habitual drinking & $857(49)$ & $874(50)$ & $568(48)$ & $584(50)$ & $579(49)$ \\
\hline Past drinker & $80(5)$ & $84(5)$ & $46(4)$ & $67(6)$ & $51(4)$ \\
\hline Diabetes mellitus & $271(15)$ & $267(15)$ & $181(15)$ & $191(16)$ & $166(14)$ \\
\hline Use of antidiabetic drugs & $141(8)$ & $155(9)$ & $96(8)$ & $101(9)$ & $99(8)$ \\
\hline Hypercholesterolemia & 599 (34) & $591(34)$ & 392 (33) & $410(35)$ & $388(33)$ \\
\hline Previous cardiovascular disease & $47(3)$ & $59(3)$ & $34(3)$ & $41(3)$ & $31(3)$ \\
\hline
\end{tabular}

Abbreviations: ACEls, angiotensin converting enzyme inhibitors; ARBs, angiotensin receptor blockers; CCBs, calcium channel blockers; HOMED-BP, Hypertension Objective Treatment Based on Measurement by Electrical Devices of Blood Pressure.

Home blood pressure was the average of the morning readings over 5 days immediately preceding the clinic visit. The clinic blood pressure was the average of two consecutive measurements. Diabetes mellitus is a fasting plasma glucose of $7.0 \mathrm{mmoll}^{-1}\left(126 \mathrm{mg} \mathrm{dl}^{-1}\right)$ or more, or an $\mathrm{HbA}_{1 \mathrm{c}}$ of $6.5 \%$ or more, or treatment with oral antidiabetic drugs or insulin. Hypercholesterolemia is total serum cholesterol of $5.69 \mathrm{mmol}^{-1}\left(220 \mathrm{mg} \mathrm{dl}^{-1}\right)$ or more, a history of hypercholesterolemia, or taking lipid-lowering drugs. Baseline characteristics did not differ between randomized groups $(P \geqslant 0.10)$ with the exception of a trend for heart rate at home between usual and tight control group $(P=0.056)$. Asterisks denote significant differences $(P<0.0001)$ between the home and conventional measurements of blood pressure and heart rate.

$(P \geqslant 0.24)$. It averaged $129.3(13.3) / 76.1(9.4) \mathrm{mm} \mathrm{Hg}$ in patients randomized to initial treatment with ACEIs; $129.8(13.0) / 76.5(9.6)$ $\mathrm{mm} \mathrm{Hg}$ in patients started on ARBs; and 130.1 (13.3)/76.8(9.7) $\mathrm{mm} \mathrm{Hg}$ in patients randomized to CCBs. The primary end point, the broader composite cardiovascular end point stroke, ischemic heart disease and all-cause mortality occurred at similar rates in the three drug groups (Table 2; Figure 3). In a Cox regression model, there was no interaction between the blood pressure lowering and the drug arms in relation to the primary end point $(P \geqslant 0.49)$. The number of patients withdrawn for severe side effects amounted to $1(0.09 \%)$, $1(0.09 \%)$ and $5(0.43 \%)$ in the ACEIs, ARBs, and CCBs groups, respectively.

\section{Baseline vs. on-treatment $\mathrm{HBP}$ as predictor of outcome}

Exploratory analyses the whole study population showed that the increase in risk across tertiles of systolic home pressure at baseline and during follow-up was linear without evidence for a J-curve or U-curve. For the primary end point and for the broader cardiovascular end point, the $P$-values for linear trend across tertiles of the baseline systolic pressure were 0.0021 and 0.0029 and across tertiles of the follow-up systolic pressure were 0.0035 and $<0.0001$, respectively.

Depending on the outcome being considered, the correlation coefficients between the baseline and follow-up systolic HBPs were significant $(P<0.0001)$, but small ranging from 0.24 to 0.25 . With adjustments applied for randomization group, sex, age, body mass index, smoking and drinking, history of cardiovascular disease, diabetes mellitus and hypercholesterolemia (Table 3), both the baseline and on-treatment systolic HBP predicted $(P \leqslant 0.0025)$ the primary end point. In fully adjusted models, which included both the baseline and on-treatment HBP, the risk of a primary end point independently increased by $41 \%(\mathrm{CI}, 6-89 \% ; P=0.019)$ and by $47 \%$ (CI, $15-87 \% ; P=0.0020)$ for a 1-s.d. increase in the baseline $(12.5 \mathrm{~mm} \mathrm{Hg})$ and follow-up $(13.2 \mathrm{~mm} \mathrm{Hg})$ systolic HBP levels, respectively.

Figure 4 shows the absolute 5-year risk of a primary end point associated with the systolic HBP as measured at baseline and followup. With standardization to the mean values of the co-variables, the level of the on-treatment systolic home pressure corresponding with a 5 -year risk of the primary end point of $1 \%$ was $131.6 \mathrm{~mm} \mathrm{Hg}$ (CI, 131.1-132.1 mm Hg). The on-treatment systolic home pressure had been imputed in 371 patients for the primary end point and in 367 up to 381 for the other end points. However, sensitivity analyses not including those patients were confirmatory (Supplementary Table S2).

\section{DISCUSSION}

We showed in over 3000 patients that long-term adjustment of antihypertensive drug treatment based on self-measured HBP is feasible. Patients accepted monitoring HBP over a long period. Second, antihypertensive treatment guided by the HBP resulted in levels lower than in most other trials of antihypertensive therapies, in which treatment was adjusted according to the clinic blood pressure. ${ }^{28}$ Finally, the observational analysis of the all treatment groups 
combined showed that there was no J-curve. More than half of the HOMED-BP patients (55.8\%) achieved a systolic HBP $<130 \mathrm{~mm} \mathrm{Hg}$ and thereby reduced their risk of a primary cardiovascular end point to $1 \%$ or less.

Whereas in THOP $^{8}$ and HOMERUS ${ }^{9}$ follow-up was limited to 1 year, median follow-up in our current study was 5.31 years, which
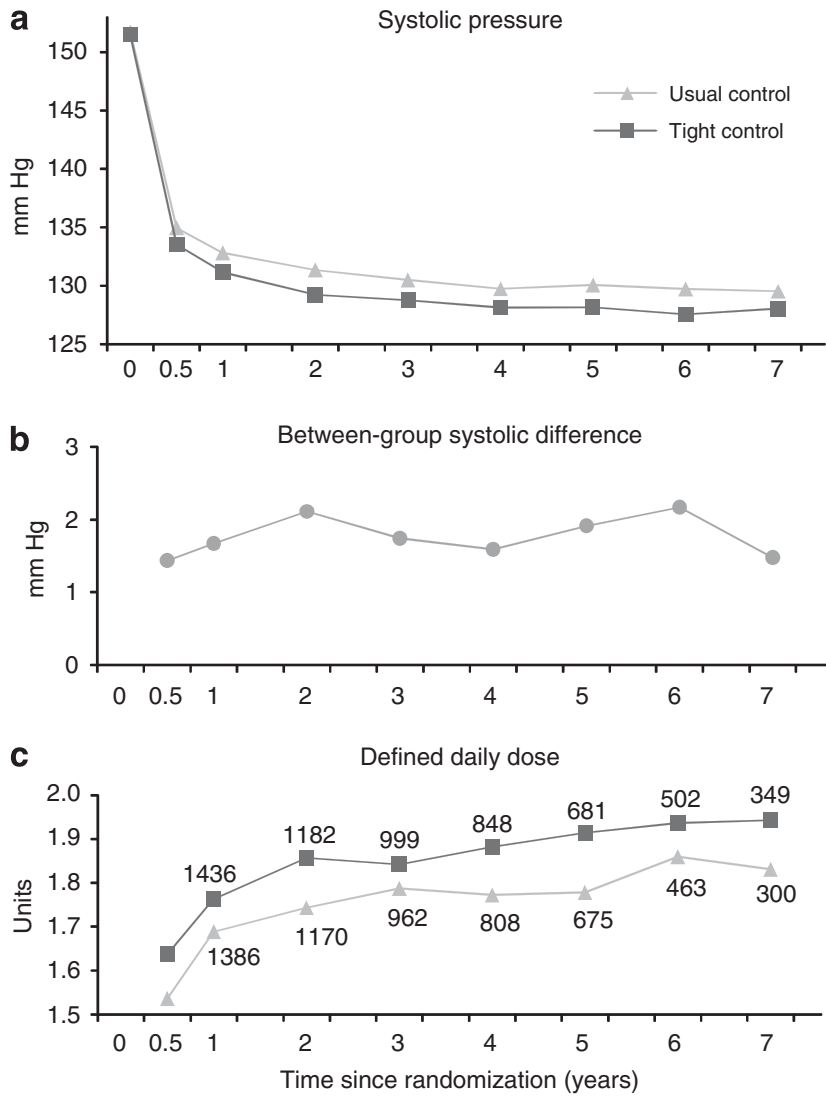

Figure 2 Follow-up of 1759 patients randomized to usual control and 1759 allocated to tight control for (a) systolic home blood pressure, (b) the between-group difference in the systolic home blood pressure and (c) the defined daily dose of the antihypertensive medications used. The numbers of patients available for follow-up at each time point are given in (c). A full color version of this figure is available at the Hypertension Research journal online. allowed to investigate cardiovascular outcome rather than blood pressure level as the primary outcome. In analyses according to the lines of randomization, however, there were no differences in the incidence of the primary end point or any other end point according to whether patients were randomized to usual $v s$. tight blood pressure control. Several points must be considered in the interpretation of these null results, of which some are general and others specific for HOMED-BP. Japanese outpatients compared with those recruited in various other parts of the worlds have a $30 \%$ lower risk of cardiovascular death, myocardial infarction or stroke. ${ }^{29}$ Furthermore, incidence rates of cardiovascular complications are generally lower in randomized clinical trials than in the general population. Our sample size estimates, based on the Ohasama population, ${ }^{22}$ assumed a rate of the primary end point in the control group of 13.0 events per 1000 patient-years, whereas it ran at only 2.96 events per 1000 patient-years in the 2 treatment groups combined. Lower than expected rates of the primary end point also occurred in several other trials conducted by Japanese $^{30}$ or International ${ }^{31}$ Research Consortia.

One issue specific for HOMED-BP was that doctors and patients were reluctant to up titrate antihypertensive drug treatment to achieve
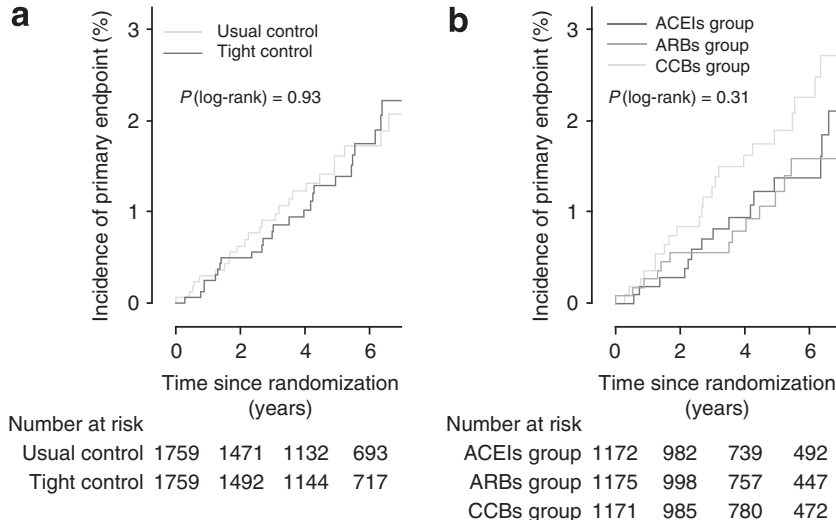

Figure 3 Cumulative rates of the primary end point in patients randomized to (a) usual and tight control of self-measured blood pressure at home and to (b) the initiation of antihypertensive drug treatment with ACEIs, ARBs or CCBs. The primary end point was a composite of cardiovascular death (ICD-10 codes I00-199), non-fatal myocardial infarction (I21) and non-fatal stroke (160, 161 and 163). A full color version of this figure is available at the Hypertension Research journal online.

Table 2 End points by target level and first-line drug

\begin{tabular}{|c|c|c|c|c|c|c|c|c|c|c|c|c|c|c|}
\hline \multirow[b]{2}{*}{ End point } & \multicolumn{2}{|c|}{$\begin{array}{l}\text { Usual } \\
\text { control }\end{array}$} & \multicolumn{2}{|c|}{$\begin{array}{c}\text { Tight } \\
\text { control }\end{array}$} & \multirow{2}{*}{$\frac{\% \Delta \text { Rate }(95 \% \mathrm{Cl})}{\text { vs. usual }}$} & \multicolumn{2}{|c|}{$A C E I S$} & \multicolumn{2}{|c|}{ ARBs } & \multicolumn{2}{|c|}{ CCBs } & \multicolumn{3}{|c|}{$\% \Delta$ Rate $(95 \%$ Cl) } \\
\hline & $n$ & Rate & $n$ & Rate & & $\mathrm{n}$ & Rate & $n$ & Rate & $n$ & Rate & ACEls vs. ARBs & CCBs vs. ACE/s & CCBs vs. ARBs \\
\hline Primary end point & 25 & 2.93 & 26 & 3.00 & $2(-41$ to 77$)$ & 16 & 2.81 & 13 & 2.28 & 22 & 3.81 & $23(-41$ to 156$)$ & $35(-29$ to 158$)$ & $67(-16$ to 231$)$ \\
\hline \multicolumn{15}{|c|}{ Fatal plus non-fatal end points } \\
\hline All cardiovascular & 49 & 5.83 & 57 & 6.64 & $14(-22$ to 67$)$ & 41 & 7.30 & 31 & 5.50 & 34 & 5.92 & $33(-17$ to 112$)$ & $-19(-49$ to 28$)$ & $8(-34$ to 75$)$ \\
\hline Stroke & 16 & 1.87 & 20 & 2.30 & $23(-36$ to 137$)$ & 11 & 1.93 & 9 & 1.57 & 16 & 2.76 & $21(-50$ to 193$)$ & $44(-33$ to 209$)$ & $74(-23$ to 294$)$ \\
\hline Ischemic heart disease & 28 & 3.31 & 25 & 2.88 & $-13(-49$ to 49$)$ & 22 & 3.89 & 19 & 3.35 & 12 & 2.07 & $17(-37$ to 116$)$ & $-47(-74$ to 7$)$ & $-38(-70$ to 28$)$ \\
\hline \multicolumn{15}{|l|}{ Mortality } \\
\hline Total & 31 & 3.62 & 27 & 3.10 & -15 ( -49 to 43$)$ & 17 & 2.97 & 16 & 2.79 & 25 & 4.30 & $6(-46$ to 111$)$ & $44(-22$ to 167$)$ & $54(-18$ to 187$)$ \\
\hline Non-cardiovascular & 26 & 3.04 & 24 & 2.75 & $-10(-48$ to 57$)$ & 15 & 2.62 & 14 & 2.44 & 21 & 3.61 & $7(-48$ to 122$)$ & 37 ( -29 to 166$)$ & 47 ( -25 to 189$)$ \\
\hline
\end{tabular}

Abbreviations: ACEIs, angiotensin converting enzyme inhibitors; ARBs, angiotensin receptor blockers; CCBs, calcium channel blockers; Cl, confidence interval.

For the target level, the group randomized to usual control was the reference. For the initiation of treatment, the last mentioned drug class is the reference. Rates are expressed in events per 1000 person-years. \% $\Delta$ Rate is the difference in rates expressed as a percentage of the rate in the reference group. The primary end point was a composite of cardiovascular death, non-fatal stroke and non-fatal myocardial infarction. All cardiovascular disease includes the primary outcome plus transient ischemic attack, angina pectoris, heart failure and peripheral arterial disease. 
Table 3 Risks associated with the systolic home blood pressure at baseline and during follow-up in 3518 participants

\begin{tabular}{|c|c|c|c|c|c|}
\hline \multirow[b]{2}{*}{ End point (number) } & \multirow[b]{2}{*}{ Model } & \multicolumn{2}{|c|}{ Baseline } & \multicolumn{2}{|c|}{ Follow-up } \\
\hline & & Hazard ratio $(95 \% \mathrm{Cl})$ & P-value & Hazard ratio $(95 \% \mathrm{Cl})$ & P-value \\
\hline \multirow[t]{2}{*}{ Primary end point (51) } & Adjusted & $1.57(1.19-2.08)$ & 0.0015 & $1.60(1.26-2.04)$ & 0.0002 \\
\hline & Fully adjusted & $1.41(1.06-1.89)$ & 0.019 & $1.47(1.15-1.87)$ & 0.0020 \\
\hline \multicolumn{6}{|l|}{ Fatal plus non-fatal end points } \\
\hline \multirow[t]{2}{*}{ All cardiovascular (106) } & Adjusted & $1.34(1.11-1.62)$ & 0.0026 & $1.47(1.23-1.75)$ & $<0.0001$ \\
\hline & Fully adjusted & $1.21(0.99-1.47)$ & 0.065 & $1.44(1.21-1.72)$ & $<0.0001$ \\
\hline \multirow[t]{2}{*}{ Stroke (36) } & Adjusted & $1.40(1.01-1.95)$ & 0.046 & $1.59(1.20-2.11)$ & 0.0011 \\
\hline & Fully adjusted & $1.24(0.88-1.76)$ & 0.22 & $1.53(1.14-2.05)$ & 0.0046 \\
\hline \multirow[t]{2}{*}{ Ischemic heart disease (53) } & Adjusted & $1.35(1.03-1.76)$ & 0.029 & $1.37(1.08-1.75)$ & 0.010 \\
\hline & Fully adjusted & $1.25(0.94-1.65)$ & 0.12 & $1.32(1.04-1.69)$ & 0.026 \\
\hline \multirow{2}{*}{ Myocardial infarction (12) } & Adjusted & $1.75(0.99-3.10)$ & 0.055 & $1.68(1.05-2.69)$ & 0.030 \\
\hline & Fully adjusted & $1.55(0.84-2.83)$ & 0.16 & $1.57(0.98-2.50)$ & 0.058 \\
\hline \multicolumn{6}{|l|}{ Mortality } \\
\hline \multirow[t]{2}{*}{ Total (58) } & Adjusted & $1.04(0.79-1.35)$ & 0.80 & $1.24(0.99-1.57)$ & 0.067 \\
\hline & Fully adjusted & $0.98(0.75-1.29)$ & 0.90 & $1.25(0.97-1.60)$ & 0.080 \\
\hline \multirow[t]{2}{*}{ Cardiovascular (8) } & Adjusted & $2.33(1.11-4.91)$ & 0.026 & $1.71(0.89-3.28)$ & 0.11 \\
\hline & Fully adjusted & $2.22(1.03-4.80)$ & 0.041 & $1.46(0.77-2.74)$ & 0.24 \\
\hline \multirow[t]{2}{*}{ Non-cardiovascular (50) } & Adjusted & $0.91(0.68-1.22)$ & 0.54 & $1.17(0.91-1.52)$ & 0.22 \\
\hline & Fully adjusted & $0.87(0.64-1.17)$ & 0.36 & $1.22(0.94-1.59)$ & 0.14 \\
\hline
\end{tabular}

Hazard ratios express the risk associated with 1-s.d. increase in systolic home blood pressure. The s.d.s were 12.5 and $13.2 \mathrm{~mm} \mathrm{Hg}$ for the home blood pressure at baseline and follow-up, respectively. The co-variables in adjusted model were randomization group and baseline characteristics: sex, age, body mass index, current smoking and drinking, history of cardiovascular disease, diabetes mellitus and hypercholesterolemia. In fully adjusted models, the baseline home blood pressure was additionally adjusted for the home blood pressure during follow-up and vice versa. Fully adjusted models include the same co-variables. The correlation coefficients between the baseline and follow-up home blood pressures were 0.24-0.25.

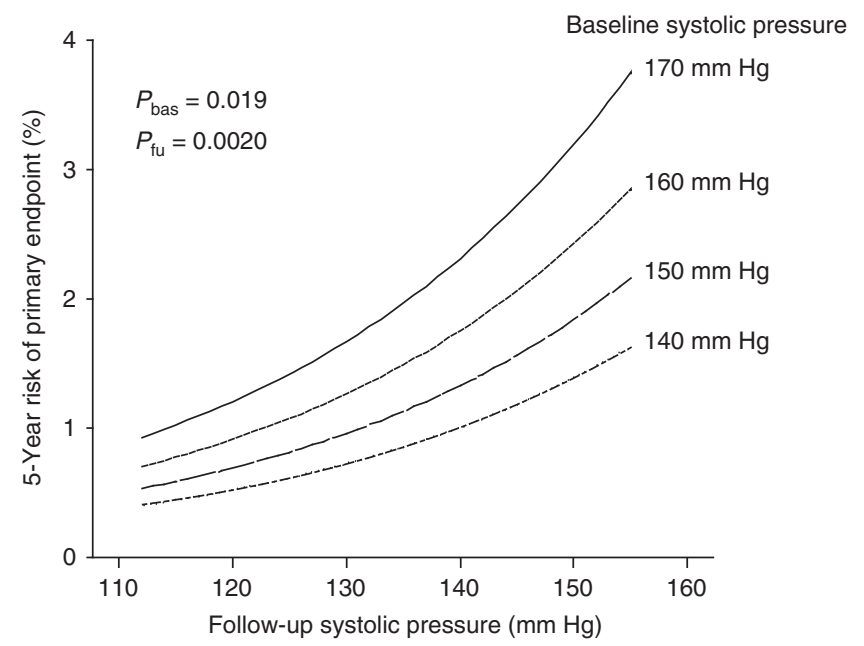

Figure 4 Five-year absolute risk of a primary end point associated with the systolic home blood pressure at baseline and during follow-up. In each patient, home measurement was the average of the morning readings available over up to 5 days immediately preceding the clinic visit. To compute the risk functions, the follow-up blood pressure was the last available measurement in patients without events and otherwise the level recorded 6 months before an event. $P_{\mathrm{bas}}$ and $P_{\mathrm{fu}}$ indicate the significance of risk function associated with systolic home blood pressure at baseline and follow-up, respectively.

the stringent blood pressure targets outlined in the protocol and often overruled or did not adhere to the centrally generated treatment recommendations. The rate at which treatment recommendations were implemented during the first 2 years after randomization was low $<30 \%$. As a result, the HBP was only $1.3 \mathrm{~mm} \mathrm{Hg}$ systolic and $0.8 \mathrm{~mm} \mathrm{Hg}$ diastolic lower in patients randomized to TC. Ferrari ${ }^{32}$ listed the six main reasons for maintaining an unchanged drug treatment despite higher than desired blood pressure values: the perception that the time after starting drug treatment was too short to attain its full effect; satisfaction with a clear improvement of blood pressure or with a blood pressure nearing goal; poor adherence; reduction in risk factors other than blood pressure; side effects; and normal or acceptable levels on self-measurement or white-coat hypertension. Because of the inclusion criteria requiring $\mathrm{HBP}$ of 135/85 mm Hg, HOMED-BP did not include white-coat hypertensive patients. Among 1966 Japanese physicians, interrogated in 2004-2005 and in 2007-2008, only 21.6 and $23.9 \%$ correctly recognized the reference values of hypertension based on the HBP as proposed in the Japanese guideline $(135 / 85 \mathrm{~mm} \mathrm{Hg}){ }^{33}$ In the Japan Home Versus Office Blood Pressure Measurement Evaluation study, HBP values were not properly controlled in 75 and $24 \%$ of the patients, even when their physicians evaluated them as having 'fairly good control' and 'excellent control', respectively. ${ }^{34}$

Because, in line with the small difference in the HBP, the risks of primary and secondary outcomes were similar in the randomized groups, we pooled all patients in an attempt to refine estimates of the HBP at which cardiovascular risk is minimal. As in previous analyses, ${ }^{24}$ we were careful in defining the on-treatment blood pressure excluding blood pressure levels within 6 months before an event. We limited our analysis to systolic blood pressure, because in middle-aged and older subjects, it is the overriding risk factor. ${ }^{35,36}$ Exploratory analyses across tertiles of the distribution of the systolic home pressure did not reveal any evidence for a J-curve, irrespective of whether blood pressure was measured untreated at baseline or on treatment. These findings for the first time support the concept of 'the lower, the better' for the adjustment of antihypertensive treatment based on self-measured HBP. In fully adjusted analyses, the 5-year risk of the primary end point was $1 \%$ or less, if the systolic HBP was reduced to $\sim 130 \mathrm{~mm} \mathrm{Hg}$. This threshold is $5 \mathrm{~mm} \mathrm{Hg}$ lower than 
proposed in current guidelines ${ }^{1,2}$ and $5-7 \mathrm{~mm} \mathrm{Hg}$ lower than the thresholds derived in meta-analyses of aggregate ${ }^{37}$ or individualsubject $^{38} \mathrm{HBP}$ data. Our current findings based on cardiovascular outcome also support the recommendations of the Japanese Society of Hypertension, ${ }^{2}$ who proposed that treatment should target systolic levels of $135 \mathrm{~mm} \mathrm{Hg}$ in patients of older age or with history of stroke, and $125 \mathrm{~mm} \mathrm{Hg}$ in patients of young- to middle-aged or with diabetes mellitus, kidney disease or myocardial infarction. Our study also highlights that these thresholds can be safely attained, because the incidence of severe side effects was $<0.5 \%$.

The present study must be interpreted within the context of its design. First, we enrolled mild-to-moderate (HBP of $<180 / 120 \mathrm{~mm} \mathrm{Hg}$ ) essential hypertensive patients. Although our results are representative for health care provided to middle-aged and older Japanese, they might not be applicable to other settings or ethnic groups with a different distribution of risk factors. Second, the PROBE ${ }^{12}$ design ensures that end points are blindly adjudicated, but does not protect against bias in the report of events, in particular in a trial-like HOMED-BP, in which patients had direct information on their blood pressure on a daily basis. Third, we did not assess the contributions of physicians and patients, as exemplified by treatment inertia and lack of adherence, respectively, to explain the failure to reach treatment goals in a large number of HOMED-BP patients. Factors contributing to this observation lay in network failures during the initial phase of the trial and in the fact that according to the HOMED-BP protocol clinicians could override the treatment recommendations offered by the central server. Fourth, we used the DDD index for summarizing the usage of antihypertensive drugs. Although DDD is a standard in pharmacoepidemiologic studies, ${ }^{39}$ more than one-fifth of the antihypertensive drugs are not registered to the DDD list, and some registered doses are not commonly prescribed in Japan. However, this would not affect the current results, because the same DDD scale was used in both randomized groups. Fifth, the $\sim 2-\mathrm{mm} \mathrm{Hg}$ difference was small in the analysis comparing usual and tight blood pressure control, but the analysis of the HOMED-BP cohort in the observational analysis covered a systolic range of over $40 \mathrm{~mm} \mathrm{Hg}$. Sixth, HOMED-BP was not powered to compare the three drug classes to initiate antihypertensive treatment, but the null findings across the three drug classes are compatible with the point of view that blood pressure reduction rather than drug class are driving the benefit of antihypertensive therapy. ${ }^{28}$ Finally, HOMED-BP was not set up to compare the predictive value of the home and clinic blood pressures, because the literature proving this point is overwhelming. In HOMED-BP, treatment was therefore exclusively adjusted according to self-measured HBP.

Our present findings have important implications for clinical practice. The HBP provides a more reliable estimate of a patient's true blood pressure than the clinic pressure and in this respect equals daytime ambulatory blood pressure monitoring. ${ }^{1,2}$ Lovibond et al. ${ }^{40}$ recently showed that ambulatory monitoring as a diagnostic strategy for hypertension after an initially raised reading in the clinic would reduce misdiagnosis and save costs. However, her analysis also highlighted that ambulatory monitoring should not remain the dominant strategy when blood pressure would need to be assessed at annual or shorter intervals, which is the case when antihypertensive treatment is adjusted to an individual patient's needs. After $>30$ years of research, ${ }^{41}$ in line with recent position statements, ${ }^{6,7}$ our findings therefore strengthen the central role of self-measured HBP in the clinical management of patients with suspected or proven hypertension. HOMED-BP demonstrated the long-term feasibility of adjusting antihypertensive drug treatment based on self-measured
HBP. However, the large-scale implementation of self-measured blood pressure, as advocated by Pickering et al. ${ }^{7}$ would require intensive education of doctors and patients to overcome treatment inertia and non-adherence, respectively.

\section{CONFLICT OF INTEREST}

KA received research support from Japan Research Foundation for Clinical Pharmacology and lecturing fees from Daiichi Sankyo, Kyowa Hakko Kirin, Merck Sharpe and Dohme, Tanabe-Mitsubishi, Novartis and Novo Nordisk. TOh received lecturing fees from Asteras, AstraZeneca, Daiichi Sankyo Dainippon-Sumitomo, Kyowa Hakko Kirin, Merck Sharpe and Dohme, Novartis, Pfizer, Takeda and Tanabe-Mitsubishi. HM received lecturing fees from Merck Sharpe and Dohme. JAS received consulting and lecturing fees and research support from AstraZeneca, Daiichi-Sankyo, Tanabe-Mitsubishi, Novartis, Pfizer and Sigma-Tau. YI received lecturing fees and research support from Asteras, AstraZeneca, Daiichi Sankyo, Dainippon-Sumitomo, Merck Sharpe and Dohme, Novartis, Pfizer, Takeda and Tanabe-Mitsubishi. Omron Healthcare gave research support to KA, YI, HM and TOh. The remaining authors declared no conflict of interest.

\section{ACKNOWLEDGEMENTS}

The Japanese Society of Hypertension endorsed the HOMED-BP trial. Part of the work was presented at the 34th Annual Scientific Meeting of the Japanese Society of Hypertension, Utsunomia, Japan, as late-breaking trial. The study is funded by grants from the Japan Cardiovascular Research Foundation, the Japan Arteriosclerosis Prevention Fund and Tohoku University. Fujitsu Systems East Limited (Tokyo, Japan) and Omron Healthcare Co. (Kyoto, Japan) developed and maintained the internet-based infrastructure for the measurement of blood pressure at home and the management of patients.

1 Mancia G, De Backer G, Dominiczak A, Cifkova R, Fagard R, Germano G, Grassi G, Heagerty AM, Kjeldsen SE, Laurent S, Narkiewicz K, Ruilope L, Rynkiewicz A, Schmieder RE, Struijker Boudier HA, Zanchetti A, Vahanian A, Camm J, De Caterina R, Dean V, Dickstein K, Filippatos G, Funck-Brentano C, Hellemans I, Kristensen SD, McGregor K, Sechtem U, Silber S, Tendera M, Widimsky P, Zamorano JL, Erdine S, Kiowski W, Agabiti-Rosei E, Ambrosioni E, Lindholm LH, Manolis A, Nilsson PM, Redon J, Struijker-Boudier HA, Viigimaa M, Adamopoulos S, Bertomeu V, Clement D, Farsang C, Gaita D, Lip G, Mallion JM, Manolis AJ, O'Brien E, Ponikowski P, Ruschitzka F, Tamargo J, van Zwieten P, Waeber B, Williams B. 2007 Guidelines for the management of arterial hypertension: the task force for the management of arterial hypertension of the European Society of Hypertension (ESH) and of the European Society of Cardiology (ESC). Eur Heart J 2007; 28: 1462-1536.

2 Ogihara T, Kikuchi K, Matsuoka H, Fujita T, Higaki J, Horiuchi M, Imai Y, Imaizumi T, Ito S, Iwao H, Kario K, Kawano Y, Kim-Mitsuyama S, Kimura G, Matsubara H, Matsuura H, Naruse M, Saito I, Shimada K, Shimamoto K, Suzuki H, Takishita S, Tanahashi N, Tsuchihashi T, Uchiyama M, Ueda S, Ueshima H, Umemura S, Ishimitsu T, Rakugi H. The Japanese Society of Hypertension guidelines for the management of hypertension (JSH 2009). Hypertens Res 2009; 32: 3-107.

3 Parati G, Stergiou GS, Asmar R, Bilo G, de Leeuw P, Imai Y, Kario K, Lurbe E, Manolis A, Mengden T, O'Brien E, Ohkubo T, Padfield P, Palatini P, Pickering T, Redon J, Revera M, Ruilope LM, Shennan A, Staessen JA, Tisler A, Waeber B, Zanchetti A, Mancia G. European Society of Hypertension guidelines for blood pressure monitoring at home: a summary report of the second international consensus conference on home blood pressure monitoring. J Hypertens 2008; 26: 1505-1526.

4 Asayama K, Ohkubo T, Kikuya M, Metoki H, Hoshi H, Hashimoto J, Totsune K, Satoh H, Imai Y. Prediction of stroke by self-measurement of blood pressure at home versus casual screening blood pressure measurement in relation to the JNC-7 classification: The Ohasama study. Stroke 2004; 35: 2356-2361.

5 Niiranen TJ, Hanninen MR, Johansson J, Reunanen A, Jula AM. Home-measured blood pressure is a stronger predictor of cardiovascular risk than office blood pressure: The Finn-home study. Hypertension 2010; 55: 1346-1351.

6 Pickering TG. Home blood pressure monitoring: a new standard method for monitoring hypertension control in treated patients. Nat Clin Pract Cardiovasc Med 2008; 5: 762-763.

7 Pickering TG, Miller NH, Ogedegbe G, Krakoff LR, Artinian NT, Goff D. Call to action on use and reimbursement for home blood pressure monitoring: a joint scientific statement from the American Heart Association, American Society of Hypertension, and Preventive Cardiovascular Nurses Association. Hypertension 2008; 52: 10-29.

8 Staessen JA, Den Hond E, Celis H, Fagard R, Keary L, Vandenhoven G, O'Brien ET. Antihypertensive treatment based on blood pressure measurement at home or in the physician's office: a randomized controlled trial. JAMA 2004; 291: 955-964. 
9 Verberk WJ, Kroon AA, Lenders JW, Kessels AG, van Montfrans GA, Smit AJ, van der Kuy PH, Nelemans PJ, Rennenberg RJ, Grobbee DE, Beltman FW, Joore MA, Brunenberg DE, Dirksen C, Thien T, de Leeuw PW. Self-measurement of blood pressure at home reduces the need for antihypertensive drugs: a randomized, controlled trial. Hypertension 2007; 50: 1019-1025.

10 Fujiwara T, Nishimura T, Ohkuko T, Imai Y. Rationale and design of HOMED-BP study: hypertension objective treatment based on measurement by electrical devices of blood pressure study. Blood Press Monit 2002; 7: 77-82.

11 World Medical Association Declaration of Helsinki. Recommendations guiding physicians in biomedical research involving human subjects. JAMA 1997; 277: 925-926.

12 Hansson L, Hedner T, Dahlof B. Prospective randomized open blinded end-point (PROBE) study. A novel design for intervention trials. Prospective randomized open blinded end-point. Blood Press 1992; 1: 113-119.

13 White WB, Anwar YA. Evaluation of the overall efficacy of the Omron office digital blood pressure HEM-907 monitor in adults. Blood Press Monit 2001; 6: 107-110.

14 Chonan K, Kikuya M, Araki T, Fujiwara T, Suzuki M, Michimata M, Hashimoto J, Ohkubo T, Hozawa A, Yamamoto N, Miyawaki Y, Matsubara M, Imai Y. Device for the self-measurement of blood pressure that can monitor blood pressure during sleep. Blood Press Monit 2001; 6: 203-205.

15 The sixth report of the Joint National Committee on prevention, detection, evaluation, and treatment of high blood pressure. Arch Intern Med 1997; 157: 2413-2446.

16 Guidelines Subcommittee. 1999 World Health Organization-International Society of Hypertension guidelines for the management of hypertension. J Hypertens 1999; 17: $151-183$.

17 Yusuf S, Dagenais G, Pogue J, Bosch J, Sleight P. Vitamin E supplementation and cardiovascular events in high-risk patients. The heart outcomes prevention evaluation study investigators. N Engl J Med 2000; 342: 154-160.

18 Sokolow M, Lyon TP. The ventricular complex in left ventricular hypertrophy as obtained by unipolar precordial and limb leads. Am Heart J 1949; 37: 161-186.

19 Okin PM, Roman MJ, Devereux RB, Kligfield P. Electrocardiographic identification of increased left ventricular mass by simple voltage-duration products. J Am Coll Cardiol 1995; 25: 417-423.

20 Seino Y, Nanjo K, Tajima N, Kadowaki T, Kashiwagi A, Araki E, Ito C, Inagaki N, Iwamoto Y, Kasuga M, Hanafusa T, Haneda M, Ueki K. Report of the committee on the classification and diagnostic criteria of diabetes mellitus. J Diabetes Investig 2010; 1: 212-228.

21 World Health Organization. World Health Organization Collaborating Centre for drug statistics methodology system of defined daily doses. http://www.whocc.no/atc ddd_index (Accessed 23 August 2011).

22 Yasui D, Asayama K, Ohkubo T, Kikuya M, Kanno A, Hara A, Hirose T, Obara T, Metoki H, Inoue R, Totsune K, Hoshi H, Satoh H, Imai Y. Stroke risk in treated hypertension based on home blood pressure: The Ohasama study. Am J Hypertens 2010; 23: 508-514.

23 Rosner B. Fundamentals of Biostatistics, 7th edn. Brooks/Cole, Cengage Learning, Boston, MA, USA, 2010.

24 Staessen J, Bulpitt C, Clement D, De Leeuw P, Fagard R, Fletcher A, Forette F, Leonetti G, Nissinen A, O'Malley K, Tuomilehto J, Webster J, Williams BO. Relation between mortality and treated blood pressure in elderly patients with hypertension: report of the European Working Party on high blood pressure in the elderly. BMJ 1989, 298: 1552-1556.

25 Rubin DB. Multiple Imputation for Nonresponse in Surveys. John Wiley \& Sons, Inc, Hoboken, NJ, USA, 2008

26 Hesterberg T, Moore DS, Monaghan S, Clipson A, Epstein R. Bootstrap methods and permutation tests. Introduction to the Practice of Statistics 2005; 5: 1-70.
27 Kikuya M, Hansen TW, Thijs L, Bjorklund-Bodegard K, Kuznetsova T, Ohkubo T, Richart T, Torp-Pedersen C, Lind L, Ibsen H, Imai Y, Staessen JA. Diagnostic thresholds for ambulatory blood pressure monitoring based on 10-year cardiovascular risk. Circulation 2007; 115: 2145-2152.

28 Staessen JA, Wang JG, Thijs L. Cardiovascular protection and blood pressure reduction: a meta-analysis. Lancet 2001; 358: 1305-1315.

29 Bhatt DL, Eagle KA, Ohman EM, Hirsch AT, Goto S, Mahoney EM, Wilson PW, Alberts MJ, D'Agostino R, Liau CS, Mas JL, Rother J, Smith Jr. SC, Salette G, Contant CF, Massaro JM, Steg PG. Comparative determinants of 4-year cardiovascular event rates in stable outpatients at risk of or with atherothrombosis. JAMA 2010; 304: 1350-1357.

30 Ogihara T, Saruta T, Rakugi H, Matsuoka H, Shimamoto K, Shimada K, Imai Y, Kikuchi K, Ito S, Eto T, Kimura G, Imaizumi T, Takishita S, Ueshima H. Target blood pressure for treatment of isolated systolic hypertension in the elderly: valsartan in elderly isolated systolic hypertension study. Hypertension 2010; 56: 196-202.

31 Yusuf S, Diener HC, Sacco RL, Cotton D, Ounpuu S, Lawton WA, Palesch Y, Martin RH, Albers GW, Bath P, Bornstein N, Chan BP, Chen ST, Cunha L, Dahlof B, De Keyser J, Donnan GA, Estol C, Gorelick P, Gu V, Hermansson K, Hilbrich L, Kaste M, Lu C, Machnig T, Pais P, Roberts R, Skvortsova V, Teal P, Toni D, VanderMaelen C, Voigt T, Weber M, Yoon BW. Telmisartan to prevent recurrent stroke and cardiovascular events. N Engl J Med 2008; 359: 1225-1237.

32 Ferrari P. Reasons for therapeutic inertia when managing hypertension in clinical practice in non-western countries. J Hum Hypertens 2009; 23: 151-159.

33 Obara T, Ohkubo T, Fukunaga $H$, Kobayashi M, Satoh M, Metoki H, Asayama K, Inoue R, Kikuya M, Mano N, Miyakawa M, Imai Y. Practice and awareness of physicians regarding home blood pressure measurement in japan. Hypertens Res 2010; 33: 428-434.

34 Ohkubo T, Obara T, Funahashi J, Kikuya M, Asayama K, Metoki H, Oikawa T, Takahashi H, Hashimoto J, Totsune K, Imai Y. Control of blood pressure as measured at home and office, and comparison with physicians' assessment of control among treated hypertensive patients in japan: first report of the Japan home versus office blood pressure measurement evaluation (J-HOME) study. Hypertens Res 2004; 27: 755-763.

35 Staessen J, Amery A, Fagard R. Isolated systolic hypertension in the elderly. J Hypertens 1990; 8: 393-405.

36 Franklin SS, Larson MG, Khan SA, Wong ND, Leip EP, Kannel WB, Levy D. Does the relation of blood pressure to coronary heart disease risk change with aging? The Framingham Heart Study. Circulation 2001; 103: 1245-1249.

37 Thijs L, Staessen JA, Celis H, de Gaudemaris R, Imai Y, Julius S, Fagard R. Reference values for self-recorded blood pressure: a meta-analysis of summary data. Arch Intern Med 1998; 158: 481-488.

38 Thijs L, Staessen JA, Celis H, Fagard R, De Cort P, de Gaudemaris R, Enstrom I, Imai Y, Julius S, Menard J, Mion D, Palatini P, Rosenfeld J, Shapiro D, Spence D, Stergiou G. The international database of self-recorded blood pressures in normotensive and untreated hypertensive subjects. Blood Press Monit 1999; 4: 77-86.

39 Merlo J, Wessling A, Melander A. Comparison of dose standard units for drug utilisation studies. Eur J Clin Pharmacol 1996; 50: 27-30.

40 Lovibond K, Jowett S, Barton P, Caulfield M, Heneghan C, Hobbs FD, Hodgkinson J, Mant J, Martin U, Williams B, Wonderling D, McManus RJ. Cost-effectiveness of options for the diagnosis of high blood pressure in primary care: a modelling study. Lancet 2011; 378: 1219-1230.

41 Staessen JA, Thijs L, Ohkubo T, Kikuya M, Richart T, Boggia J, Adiyaman A, Dechering DG, Kuznetsova T, Thien T, de Leeuw P, Imai Y, O'Brien E, Parati G. Thirty years of research on diagnostic and therapeutic thresholds for the self-measured blood pressure at home. Blood Press Monit 2008; 13: 352-365.

Supplementary Information accompanies the paper on Hypertension Research website (http://www.nature.com/hr)

\section{APPENDIX}

\section{Coordination and management}

Principal investigator: Y Imai.

Advisory committee: K Arakawa, M Fujishima (deceased), J Fujii, K Fukiyama, S Hisamichi, O Iimura, M Ishii, T Omae, T Saruta and K Yoshinaga.

Steering committee: I Abe, K Abe, T Abukawa, T Ashida, N Dohba, T Etoh, A Fujimura, T Fujita, A Fukui, T Gotoh, H Hama, T Hano, H Hayashi, N Hayashida, M Hayashi, K Hiramori, Y Hirai, Y Hirata, K Hiwada, K Hora, S Ichikawa, T Iida, T Ikeda, T Imaizumi, K Ishikawa, I Ito, M Ito, S Ito, D Iwaoka, K Kanamasa, T Katagiri, S Katayama, H Kawamura, Y Kawano, H Kida, K Kikuchi, G Kimura, K Kimura, H Kitaoka, S Kobayashi, K Kohara, S Kojima, I Komuro, H Kumagai, Y Kumagai, E Kusano, T Kushiro, I Kuwajima, YMaruyama, FMasani, H Matsubara, T Matsubara, M Matsumoto, H Matsuoka, H Matsuura, Y Mishima, M Miura, I Miyamori,
H Mori, H Murakami, H Muratani, M Nakagawa, K Nakao, M Naruse, I Nishio, T Ogihara, M Ohta, K Ohtsuka, Y Ohtsuka, Y Ohuchi, S Oikawa, M Okabe, K Okumura, I Saitoh, H Saitoh, T Sakata, K Saku, H Sasaki, M Seino, S Senda, K Shimada, K Shimamoto, M Shimizu, T Shiomi, K Shirato, M Sone, H Suzuki, S Suzuki, H Takahashi, M Takada, K Takeda, N Takeda, A Takeshita, S Takishita, S Tanaka, K Toba, O Tochikubo, H Tomoike, Y Ueno, S Umemura, H Urata, T Watanabe, K Yamada, T Yamaguchi, M Yamakado, Y Yamamoto, Y Yamamoto, A Yamashina, H Yokoyama and $\mathrm{M}$ Yoshimura.

Management committee: Y Imai, T Ohkubo, K Asayama, H Satoh,

Y Kondo, K Totsune and Y Miura.

Safety monitoring and information security committee: H Satoh, $\mathrm{R}$ Inoue, $\mathrm{H}$ Shishido and Y Kondo.

End point committee: H Katagiri, K Miura, A Fujiyoshi, A Kadota, N Takashima, S Nagasawa, S Torii, S Kadowaki, T Hisamatsu and Y Oka. 
Data management committee: H Metoki, S Saito, K Hosohata, T Kato, C Takahashi, M Kikuya, L Thijs and T Ohkubo.

Operation center: K Asayama, T Fujiwara, T Nishimura, Y Aoki, Y Fushimi, H Shishido, A Kohinata, Y Kanno, M Osugi, M Suzuki, M Saito, T Tamura, N Fukushima, S Sakuma, S Katada, K Sakurai, $\mathrm{M}$ Sato, $\mathrm{T}$ Hirose and T Obara.

\section{Clinical investigators}

Hokkaido: T Ando, J Anzai, S Hosoda, M Iida, K Ito, I Kinhara, M Koizumi, Y Masuda, K Matsumoto, $\mathrm{T}$ Mito, $\mathrm{T}$ Miyamura, H Morimoto, M Nakagawa, T Noto, K Oda, Y Ogawa, M Shiiki, M Shiraishi, K Shiraishi, M Tada, Y Takagawa, K Takahashi, S Tanaka and S Yonekura.

Tohoku: H Abe, M Aihara, Y Amada, Y Ando, I Aoyama, I Aoyama, F Araki, K Asayama, S Egawa, Y Emura, T Fujita, K Fukami, T Goto, T Hayakawa, Y Hayashi, T Hayashi, T Hirose, N Hiwatari, H Hoshi, $\mathrm{N}$ Imai, Y Imai, M Inoue, K Ishibashi, H Ishii, Y Ishi-kawa, M Ito, $\mathrm{H}$ Ito, T Ito, K Ito, K Ito, M Iwamoto, $\mathrm{H}$ Jin, M Kamimoto, A Kanno, S Kashima, S Kataoka, K Kawamorita, Y Kawamorita, S Kibira, K Kikuchi, K Kikuchi, M Kikuya, Y Kimura, H Kimura, M Kimura, M Kishi, A Kitabayashi, K Komai, $\mathrm{T}$ Kondo, K Kurosawa, S Kutsuzawa, S Kyogoku, K Machii, $\mathrm{H}$ Mashiko, K Matsuo, H Metoki, O Minami, H Misawa, Y Miyazaki, R Mori, H Morikawa, K Morita, T Mouri, S Nagai, K Nakamura, D Nakayama, K Nihei, K Ohira, E Ohtomo, F Okuguchi, A Omoto, Y Ono, Y Otsuka, K Saeki, H Sakuma, S Sasaki, T Sato, E Sato, S Satoho, J Seino, H Seki, M Sekino, A Shibasaki, K Shimada, Y Shimanaka, Y Shishido, K Sone, T Sugawara, H Suzuki, H Suzuki, Y Suzuki, J Tajima, Y Takagi, K Takahashi, H Takahashi, Y Takaya, H Tanaka, N Tanno, Y Tanno, G Tashima, M Techigawara, Y Tominaga, H Toyama, Y Tsukahara, H Unakami, M Wada, N Watanabe, T Watanabe, M Watanabe, S Watanabe, H Watanabe, T Yabuki, C Yagi, N Yamada, Z Yamada, T Yamagishi, N Yamamoto, H Yamamoto, H Yamamoto and H Yokkaichi.

Kanto: S Abe, M Adachi, N Akiyama, H Aoki, M Arai, T Arai, $\mathrm{S}$ Arai, $\mathrm{T}$ Cho, S Dotare, $\mathrm{T}$ Fujito, $\mathrm{K}$ Fukuda, $\mathrm{T}$ Fukutome, H Funayama, T Gomi, Y Hamada, K Hasegawa, M Hashida, A Hashimoto, Y Hatori, H Higashi, S Higashi, N Hirawa, T Honzawa, K Hori, K Horie, H Horikoshi, T Hoshino, K Ichikawa, K Ieki, C Iguchi, T Ikeda, T Iketani, M Inaba, S Inokuma, Y Ishimaru, S Ito, M Iwasaki, K Kanouzawa, S Kanouzawa, M Kato, H Kawamura, K Kimura, Y Kodama, I Koga, H Koide, T Koitabashi, N Koshikawa, T Kudo, Y Kumagai, F Kurata, M Kurosawa, K Kuwaki, T Masuda, R Matsunaga, M Miyakawa, $\mathrm{H}$ Mori, $\mathrm{T}$ Nagao, C Nakajima, M Nakamura, M Nakano, T Nakayama, K Nemoto, H Nishimura, Y Noda, S Noji, K Noma, T Noshiro, Y Nozaki, k Okamoto, K Okano, Y Ooba, E Osuga, H Saito, J Sakurai, T Sato, H Sato, T Sekihara, K Seta, J Shimizu, T Shinozaki, H Suga, M Suzuki, R Takahata,
H Takata, K Takayama, H Takigawa, T Teramoto, S Tsukagoshi, T Ueda, T Umetsu, M Ushiyama, Y Watanabe, N Yagi, C Yamada, $\mathrm{H}$ Yamaguchi, $\mathrm{M}$ Yamakado, $\mathrm{H}$ Yamamoto, $\mathrm{T}$ Yamamoto, S Yamashina, M Yanagisawa, F Yasuda, S Yatagai and H Yoshimatsu. Chu-bu and Hokuriku: N Adachi, F Akaoka, S Akira, F Ando, S Asai, A Asaji, S Asato, K Goto, K Hayashi, N Hieda, H Higashi, K Hirahara, H Horie, M Hoshiai, T Iida, T Ise, J Ishiguro, S Ishikawa, A Ito, J Kamijo, S Kato, N Kato, Y Kawamura, I Kawamura, H Kobayashi, N Kojima, Y Koyama, M Kozuka, K Kuroda, T Matsu, H Matsumoto, J Mihara, H Mori, T Morise, A Naito, T Nakagawa, S Nakajima, T Nakamura, H Nakayama, H Nishino, O Nojiri, T Ohno, N Ohya, N Okanishi, K Okazaki, S Oohashi, T Ookura, T Saeki, R Saito, K Sakakura, K Satake, M Senga, K Sugiura, S Sugiyama, Y Suzaki, S Suzuki, C Takaeda, S Takahashi, Y Takahira, H Takakuwa, H Takakuwa, K Takasawa, M Takata, N Takeuchi, N Takeuchi, H Tamagaki, Y Terada, M Tobe, K Uchiba, K Uwatoko, Y Yamaguchi, Y Yamamoto, H Yamamoto and S Yokoyama.

Kansai: M Amemori, S Fujita, M Fujiwara, S Goto, Y Hamaguchi, K Hayashi, N Hirobe, N Imai, M Iwane, T Kanaya, K Kanemasa, J Kasahara, H Kato, S Katsuya, H Kishima, K Kitayama, M Koide, K Komaki, K Konishi, Y Kurimoto (deceased), T Majima, A Masui, M Nagai, H Nagai, K Nagao, K Nakamura, K Nakamuta, S Nishi, A Nogami, S Ono, T Orito, N Sakamoto, I Sano, S Sawada, H Sawaoka, H Shimakoshi, Y Shimakoshi, K Shirai, H Suzuki, N Suzuki, N Takahashi, N Takeda, Y Takeda, Y Takemoto, T Takenaka, K Tamai, Y Terayama, M Ueda, T Ueda, I Watanabe, T Yamaguchi, O Yamaoka, K Yasui, S Yo, K Yoshida and H Yoshikawa.

Chu-goku: T Furue, Y Furukawa, M Gen, M Harada, K Iwasaki, M Kahara, M Kamura, K Kida, J Minami, K Mizuno, K Murata, Y Nakamura, K Nakayasu, C Ogurusu, A Ohtahara, M Osakata, S Sasaki, N Sasaki, H Sugiura, S Tenou, A Tokunaga, Y Tominaga (deceased) and T Yoshimoto.

Shikoku: M Arizumi, K Fujino, T Fukui, S Furumoto, W Furumoto, T Inoue, R Kawamoto, M Kimura, Y Kitami, A Kobaru, F Kouno, C Matsumoto, T Matsuno, S Mizobuchi, H Mizobuchi, S Nishiyama, T Okabe, T Okura, A Ota, M Takeuchi, S Ueta, H Yamamoto, T Yokoi and $\mathrm{K}$ Yoshida.

Kyusyu and Okinawa: K Abe, S Arima, T Asato, T Aso, T Endo, Y Endo, T Fujino, Y Fujishima, K Funatsu, S Hamasaki, O Hano, Y Hirooka, C Hirota, T Homma, Y Inobe, J Inoue, T Iwaoka, H kamiya, Y Karimata, Y Kimura, K Kitano, H Koga, M Kouno, A Kuwahara, Y Masuda, J Miyagi, Y Miyazaki, Y Muta, M Nagata, N Nagayoshi, H Nakamura, Y Nakamura, H Nakano, S Naomi, K Ninomiya, F Omori, T Ono, K Onoyama, W Oobayashi, K Oshima, H Ozaki, K Sasaki, R Shindo, M Shiraki, R Sunagawa, S Suzuki, Y Takagi, K Takano, K Takashiba, Y Takeshita, M Tohaya, K Tohyama, H Tomori, H Urata, N Wake, S Yamada and H Yoshii. 